\title{
Transversus abdominis and core stability: has the pendulum swung?
}

\author{
G T Allison, ${ }^{1}$ S L Morris²
}

${ }^{1}$ School of Physiotherapy, Curtin University of Technology, Perth, Australia; ${ }^{2}$ The University of Western Australia, Perth, Australia

Correspondence to: Dr Garry T Allison, Associate Professor of Neuroscience and Trauma Physiotherapy, School of Physiotherapy, Curtin Health Innovation Research Institute, Curtin University of Technology and Royal Perth Hospital Department of Physiotherapy, GPO Box U1987, Perth, Western Australia 6845:

g.allison@curtin.edu.au

Accepted 8 April 2008

Published Online First 4 July 2008

\section{ABSTRACT}

In the past decade there has been a focus on isolated transversus abdominis activation and how it contributes to lumbo-pelvic stability. This rationale has not only influenced the management of chronic low back pain (LBP); it has also been included in exercises for many other pathologies of the lower and upper limb and also for prophylaxis in pain-free subjects.

The rationale that the feedforward bilateral muscle activation of the transversus abdominis stabilises the segmental lumbar spine is based on the reports that, unlike other trunk muscles, transversus abdominis is activated independently of the direction of any spinal perturbation. ${ }^{12}$ This finding implies that it plays an important role in spinal stability. The finding that individuals with low back pain or normal subjects with anxiety and stress appear to have altered timing of feedforward onsets of transversus abdominis reinforces the case for the presence of a motor control dysfunction. ${ }^{3-6}$ It is often inferred that such a dysfunctional pattern corresponds to less than optimal core stability.

Such an inference - that altered timing of the transversus abdominis leads to poor core stability is popular in the literature but on further inspection fundamental evidence is lacking.

Firstly, the literature very quickly generalises the research findings of unilateral transversus abdominis activation to a bilateral pattern. In rapid unilateral arm raising (the preferred research model) this assumption is not valid. The contra lateral side preactivates the deltoid but in most normal controls the ipsilateral side is significantly lagging. ${ }^{1}$ This critical finding suggests that, although some studies show that bilateral activation of transversus abdominis is able to stiffen the spine, $^{7}$ such findings do not correspond to the unilateral arm-raising task. That is, although they may provide some evidence that the bilateral activation of the transversus abdominis provides some degree of spinal stiffening (albeit mostly in flexion), bilateral feedforward activation of transversus abdominis is not the normal activation pattern for unilateral arm raising. ${ }^{12}$

Secondly, when arm flexion is performed using alternate arms, the transversus abdominis (left and right) are clearly directionally specific. ${ }^{18}$ The previous reports that transversus abdominis (left) is not directionally specific refers to the comparison of flexion and extension of the same (right) arm. This may reflect the difference in the strategy of arm movement, not the actual perturbing force acting on the spine due to the different directions of arm movement. The feedforward activation of the transversus abdominis on the contralateral side to arm movement is related to the rotatory torque acting on the spine and the degree of asymmetry between sides is related to the magnitude of this torque. ${ }^{2}$

As the name infers, transversus abdominis holds true to the concept of form and function since it is most sensitive to torques parallel to the muscle fibres. Transversus abdominis shows directional specificity based on the direction of the perturbation, ${ }^{12}$ and under certain types of movement it is likely to be synergistically active with other leg and trunk muscles in a diagonal rather than the corset action. ${ }^{12}$ Bilateral arm raising that generates a sagittal plane torque (ie, no significant rotatory torque) makes the transversus abdominis activation more symmetrical (corset-like) but also delays the activation. ${ }^{2}$ Hodges et al ${ }^{9}$ demonstrated that three of eight normal pain-free control subjects did not have feedforward responses in $70 \%$ of trials during bilateral arm raising. We propose that this is not due to "less than optimal stability" but rather a normal variation of motor control related to the lack of trunk rotation perturbation. Delayed activation of transversus abdominis in patients with low back pain may be more related to the lack of trunk rotation used in the arm raise by these subjects than to specific motor control problems with transversus abdominis. The activation pattern and onsets of this muscle just may be a better marker of this change in movement strategy than other trunk muscles. The isolated bilateral transversus abdominis activation training strategy, if it does provide a mechanical stiffness of the spine in pathological populations, is therefore more likely to be a compensatory control strategy than a correction of normal patterns of activation. This compensatory training strategy may be a cortical process to normalise movement control. This then re-establishes a normal asymmetrical transversus abdominis action during rotation tasks within a complex muscle synergy rather than correcting a single dysfunctional muscle.

It follows that, although bilateral transversus abdominis isolation has demonstrated some clinical utility, the assumption that it plays a significant and direct mechanical role in stability of the spine is unclear. Furthermore, the bilateral feedforward response is not a normal pattern in predictable rotation perturbations. The idea that this isolated muscle pattern should be taught prophylactically in normal pain-free athletes is at best controversial. ${ }^{10}$ Whatever the clinical utility of the intervention, the mechanistic rationale cannot be based on the presumption that the directional invariant bilateral feedforward response of transversus abdominis is acting as a corset stabiliser and 
is the normal pattern for all spinal perturbations. Similarly, care has to be taken in the interpretation that all other activation patterns represent motor control dysfunction and that this can be translated into a mechanical inference that these individuals have less than optimal core stability. The evidence is just not there.

Competing interests: None.

Funding: SLM received support during her doctoral studies from the NHMRC Dora Lush Biomedical Science Scholarship.

\section{REFERENCES}

1. Allison GT, Morris SL, Lay B. Feedforward responses of transversus abdominis are directionally specific and act asymmetrically: implications for core stability theories. J Orthop Sports Phys Ther 2008;38:228-37.

2. Morris SL, Lay B, Allison GT. Factor analysis of trunk muscle activation patterns to rapid arm raising. APA National Conference - 15th Biennial Conference Musculoskeletal Physiotherapy Australia. Cairns, Queensland, Australia: 2007.
3. Hodges PW, Richardson CA. Inefficient muscular stabilization of the lumbar spine associated with low back pain. A motor control evaluation of transversus abdominis. Spine 1996;21:2640-50.

4. Hodges PW, Richardson CA. Feedforward contraction of transversus abdominis is not influenced by the direction of arm movement. Exp Brain Res 1997;114:362-70.

5. Hodges PW, Richardson CA. Transversus abdominis and the superficial abdominal muscles are controlled independently in a postural task. Neurosci Lett 1999:265:91-4.

6. Hodges PW, Moseley GL, Gabrielsson A, Gandevia SC. Experimental muscle pain changes feedforward postural responses of the trunk muscles. Exp Brain Res 2003;151:262-71.

7. Hodges $\mathbf{P}$, Kaigle Holm A, Holm S, et al. Intervertebral stiffness of the spine is increased by evoked contraction of transversus abdominis and the diaphragm: in vivo porcine studies. Spine 2003;28:2594-601.

8. Allison GT, et al. Laterality responses during Anticipatory Postural Adjustments in Transversus Abdominis: a repeatability study. 18th International Conference of ISGPR. Burlington, VT: University of Vermont, 2007.

9. Hodges $\mathbf{P}$, Cresswell A, Thorstensson A. Preparatory trunk motion accompanies rapid upper limb movement. Exp Brain Res 1999;124:69-79.

10. Allison GT. The push - throw continuum and core stability - are Physiotherapists teaching the correct motor patterns? in APA National Conference - Sports Physiotherapy Australia. Cairns, Queensland, Australia: 2007.

\section{BMJ Careers online re-launches}

BMJ Careers online has re-launched to give you an even better online experience. You'll still find our online services such as jobs, courses and careers advice, but now they're even easier to navigate and quicker to find.

New features include:

- Job alerts - you tell us how often you want to hear from us with either daily or weekly alerts

- Refined keyword searching making it easier to find exactly what you want

- Contextual display - when you search for articles or courses we'll automatically display job adverts relevant to your search

- Recruiter logos linked directly to their organisation homepage - find out more about the company before you apply

- RSS feeds now even easier to set up

Visit careers.bmj.com to find out more. 


\section{CORRECTION}

There was an error in the pagination of the articles published in the October and November 2008 issues of the journal. Please see a corrected list of citations below. The journal apologises for this error.

Khan KM. Preventing ACL injuries, turning research into practice and avoiding media ambush. Br J Sports Med 2008;42:483-4. should be Khan KM. Preventing ACL injuries, turning research into practice and avoiding media ambush. $\mathrm{Br} J$ Sports Med 2008;42:783-4.

Gregory PL, Seah R, Pollock N. What to tell the media-or not: consensus guidelines for sports physicians. $\mathrm{Br} J$ Sports Med 2008;42:485-8. should be Gregory PL, Seah R, Pollock N. What to tell the media-or not: consensus guidelines for sports physicians. $\mathrm{Br} J$ Sports Med 2008;42:785-8.

Fagan V, Delahunt E. Patellofemoral pain syndrome: a review on the associated neuromuscular deficits and current treatment options. Br J Sports Med 2008;42:489_ 95. should be Fagan V, Delahunt E. Patellofemoral pain syndrome: a review on the associated neuromuscular deficits and current treatment options. Br J Sports Med 2008;42:789-95.

Beltrami FG, Hew-Butler T, Noakes TD. Drinking policies and exercise-associated hyponatraemia: is anyone still promoting overdrinking? Br J Sports Med 2008;42:496501. should be Beltrami FG, Hew-Butler T, Noakes TD. Drinking policies and exerciseassociated hyponatraemia: is anyone still promoting overdrinking? $\mathrm{Br} J$ Sports Med 2008;42:796-801.

Diehl JJ, Pirozzolo JJ, Best TM. The practice of primary care sports medicine in the USA. Br J Sports Med 2008;42:506-9. should be Diehl JJ, Pirozzolo JJ, Best TM. The practice of primary care sports medicine in the USA. Br J Sports Med 2008;42:806-8.

Hides J, Stanton W, Freke M, et al. MRI study of the size, symmetry and function of the trunk muscles among elite cricketers with and without low back pain. Br J Sports Med 2008;42:509-13. should be Hides J, Stanton W, Freke M, et al. MRI study of the size, symmetry and function of the trunk muscles among elite cricketers with and without low back pain. $\mathrm{Br} J$ Sports Med 2008;42:809-13

Kukidome T, Shirai K, Kubo J, et al. MRI evaluation of body composition changes in wrestlers undergoing rapid weight loss. $\mathrm{Br} \mathrm{J}$ Sports Med 2008;42:514-18. should be Kukidome T, Shirai K, Kubo J, et al. MRI evaluation of body composition changes in wrestlers undergoing rapid weight loss. $\mathrm{Br} J$ Sports Med 2008;42:814-18.
Zhang Y, Lin Z, Hu Y, et al. Effect of Ganoderma lucidum capsules on $T$ lymphocyte subsets in football on "living hightraining low". Br J Sports Med 2009;42: 519-22. should be Zhang Y, Lin Z, Hu Y, et al. Effect of Ganoderma lucidum capsules on T lymphocyte subsets in football on "living high-training low". $\mathrm{Br} J$ Sports Med 2009;42:819-22.

Edwards AM, Wells C, Butterly R. Concurrent inspiratory muscle and cardiovascular training differentially improves both perceptions of effort and $5000 \mathrm{~m}$ running performance compared with cardiovascular training alone. $\mathrm{Br} J$ Sports Med 2009;42:523-7. should be Edwards AM, Wells C, Butterly R. Concurrent inspiratory muscle and cardiovascular training differentially improves both perceptions of effort and $5000 \mathrm{~m}$ running performance compared with cardiovascular training alone. $\mathrm{Br} J$ Sports Med 2009;42:823-7.

Baron B, Noakes TD, Dekerle J, et al. Why does exercise terminate at the maximal lactate steady state intensity? $\mathrm{Br} J$ Sports Med 2008;42:528-33. should be Baron B Noakes TD, Dekerle J, et al. Why does exercise terminate at the maximal lactate steady state intensity? $\mathrm{Br} J$ Sports Med 2008;42:828-33.

Ogai R, Yamane M, Matsumoto $\mathrm{T}$, et al. Effects of petrissage massage on fatigue and exercise performance following intensive cycle pedalling. $\mathrm{Br} J$ Sports Med 2008;42:534-8. should be Ogai R, Yamane M. Matsumoto $T$, et al. Effects of petrissage massage on fatigue and exercise performance following intensive cycle pedalling. $\mathrm{Br} J$ Sports Med 2008;42:834-8.

Sandrock M, Schulze C, Schmitz D, et al. Physical activity throughout life reduces the atherosclerotic wall process in the carotid artery. Br J Sports Med 2008;42:539-44. should be Sandrock M, Schulze C, Schmitz D, et al. Physical activity throughout life reduces the atherosclerotic wall process in the carotid artery. $\mathrm{Br} J$ Sports Med 2008;42:839-44.

Ferrari M, Bonella F, Benini L, et al. Acid reflux into the oesophagus does not influence exercise-induced airway narrowing in bronchial asthma. $\mathrm{Br} J$ Sports Med 2008;42:545-9. should be Ferrari M Bonella F, Benini L, et al. Acid reflux into the oesophagus does not influence exerciseinduced airway narrowing in bronchial asthma. Br J Sports Med 2008;42:845-9.

Randolph CC. Commentary on Acid reflux into the oesophagus does not influence exercise-induced airway narrowing in bronchial asthma. Br J Sports Med 2008:42:549_ 50. should be Randolph CC. Commentary on Acid reflux into the oesophagus does not influence exercise-induced airway narrowing in bronchial asthma. $\mathrm{Br} J$ Sports Med 2008;42:849-50.
Bradshaw CJ, Bundy M, Falvey E. The diagnosis of longstanding groin pain: a prospective clinical cohort study. $\mathrm{Br} J$ Sports Med 2008;42:551-4. should be Bradshaw CJ, Bundy M, Falvey E. The diagnosis of longstanding groin pain: a prospective clinical cohort study. $\mathrm{Br} J$ Sports Med 2008;42:851-4.

Zoumalan CI, Blumenkranz MS, McCulley TJ, et al. Severe surfing-related ocular injuries: the Stanford Northern Californian experience. Br J Sports Med 2008;42:555-7. should be Zoumalan CI. Blumenkranz MS, McCulley TJ, et al. Severe surfing-related ocular injuries: the Stanford Northern Californian experience. $\mathrm{Br} I$ Sports $\mathrm{Med}$ 2008;42:855-7.

Banffi G, Krajewska M, Melegati G, et al. Effects of whole-body cryotherapy on haematological values in athletes. $\mathrm{Br} J$ Sports Med 2008;42:558. should be Banffi G Krajewska M, Melegati G, et al. Effects of whole-body cryotherapy on haematological values in athletes. $\mathrm{Br} J$ Sports Med 2008;42:858.

Schwellnus $\mathbf{M}$. SportsMedUpdate. $\mathrm{Br} J$ Sports Med 2008;42:559-60. should be Schwellnus M. SportsMedUpdate. $\mathrm{Br} J$ Sports Med 2008;42:859-60.

Khan KM. Debating transversus abdominis, the "exercise pill" and whether flying limits athletes' performance on arrival. Br J Sports Med 2008;42:561. should be Khan KM Debating transversus abdominis, the "exercise pill" and whether flying limits athletes' performance on arrival. $\mathrm{Br} J$ Sports $\mathrm{Med}$ 2008;42:861.

Warden SJ, Fuchs RK. Are "exercise pills" the answer to the growing problem of physical inactivity? $\mathrm{Br} J$ Sports Med 2008;42:562-3. should be Warden SJ Fuchs RK. Are "exercise pills" the answer to the growing problem of physical inactivity? Br J Sports Med 2008;42:862-3

Cook J. Jumping on bandwagons: taking the right clinical message from research. $\mathrm{Br} J$ Sports Med 2008;42:563. should be Cook J. Jumping on bandwagons: taking the right clinical message from research. $\mathrm{Br} J$ Sports Med 2008;42:863.

Kuipers H, Van't Hullenaar GAC, Pluim BM, et al. Four weeks' corticosteroid inhalation does not augment maximal power output in endurance athletes. $\mathrm{Br} J$ Sports Med 2008;42:568-71. should be Kuipers H, Van't Hullenaar GAC, Pluim BM, et al. Four weeks' corticosteroid inhalation does not augment maximal power output in endurance athletes. $\mathrm{Br} J$ Sports Med 2008;42 868-71.

du Toit C, Stieler M, Saunders R, et al Diagnostic accuracy of power Doppler ultrasound in patients with chronic tennis elbow. Br J Sports Med 2008;42:572-6. should be du Toit C, Stieler M, Saunders R, et al. 
Diagnostic accuracy of power Doppler ultrasound in patients with chronic tennis elbow. Br J Sports Med 2008;42:872-6.

Geertsema C, Williams AB, Dzendrowskyj $\mathrm{P}$, et al. Effect of commercial airline travel on oxygen saturation in athletes. $\mathrm{Br} J$ Sports Med 2008;42:577-81. should be Geertsema C, Williams AB, Dzendrowskyj $\mathrm{P}$, et al. Effect of commercial airline travel on oxygen saturation in athletes. $\mathrm{Br} J$ Sports Med 2008;42:877-81.

Gratze G, Mayer H, Luft FC, et al. Determinants of fast marathon performance: low basal sympathetic drive, enhanced postcompetition vasodilation and preserved cardiac performance after competition. Br J Sports Med 2008;42:582-8. should be Gratze G, Mayer H, Luft FC, et al. Determinants of fast marathon performance: low basal sympathetic drive, enhanced postcompetition vasodilation and preserved cardiac performance after competition. Br J Sports Med 2008;42:882-8.

Bessa A, Nissenbaum M, Monteiro A, et al. High-intensity ultraendurance promotes early release of muscle injury markers. $\mathrm{Br} J$ Sports Med 2009;42:589-93. should be Bessa A, Nissenbaum M, Monteiro A, et al. Highintensity ultraendurance promotes early release of muscle injury markers. $\mathrm{Br} J$ Sports Med 2009;42:889-93.

Borrione P, Rizzo M, Spaccamiglio A, et al. Sport-related hyperhomocysteinaemia: a putative marker of muscular demand to be noted for cardiovascular risk. Br J Sports Med 2008;42:594-600. should be Borrione P, Rizzo M, Spaccamiglio A, et al. Sport-related hyperhomocysteinaemia: a putative marker of muscular demand to be noted for cardiovascular risk. $\mathrm{Br} J$ Sports $\mathrm{Med}$ 2008;42:894-900.

Stamatakis E, Chaudhury M. Temporal trends in adults' sports participation patterns in England between 1997 and 2006: the Health Survey for England. Br J Sports Med 2008;42:601-8. should be Stamatakis E, Chaudhury M. Temporal trends in adults' sports participation patterns in England between 1997 and 2006: the Health Survey for England. $\mathrm{Br} J$ Sports Med 2008;42: 901-8.

Nichols AW. Sports medicine clinical trial research publications in academic medical journals between 1996 and 2005: an audit of the PubMed MEDLINE database. Br J Sports Med 2008;42:609-21. should be Nichols AW. Sports medicine clinical trial research publications in academic medical journals between 1996 and 2005: an audit of the PubMed MEDLINE database. Br J Sports Med 2008;42:909-21.

Shimada H, Suzuki T, Kimura Y, et al. Effects of an automated stride assistance system on walking parameters and muscular glucose metabolism in elderly adults. $\mathrm{Br} J$ Sports Med 2008;42:622-29. should be
Shimada H, Suzuki T, Kimura Y, et al. Effects of an automated stride assistance system on walking parameters and muscular glucose metabolism in elderly adults. $\mathrm{Br} J$ Sports Med 2008;42:922-9.

Allison GT, Morris SL. Transversus abdominis and core stability: has the pendulum swung? Br J Sports Med 2008;42:630-1. should be Allison GT, Morris SL Transversus abdominis and core stability: has the pendulum swung? Br J Sports Med 2008;42:930-1.

Kasahara S, Mashiko H, Niwa S-I. Superior performance in WAIS-R block design among top-level rugby players. $\mathrm{Br} J$ Sports Med 2008;42:632-3. should be Kasahara S, Mashiko H, Niwa S-I. Superior performance in WAIS-R block design among top-level rugby players. $\mathrm{Br} J$ Sports Med 2008;42: 932-3.

Blatteau J-E, Pény C, Pontier J-M, et al. Influence of repetitive open sea dives and physical exercises on right-to-left shunting in healthy divers. $\mathrm{Br} J$ Sports Med 2009;42:634-6. should be Blatteau J-E, Pény C, Pontier J-M, et al. Influence of repetitive open sea dives and physical exercises on right-to-left shunting in healthy divers. Br J Sports Med 2009;42:934-6.

Schwellnus M. SportsMedUpdate. $\mathrm{Br} J$ Sports Med 2008;42:637-8. should be Schwellnus M. SportsMedUpdate. $\mathrm{Br} J$ Sports Med 2008;42:937-8. 